\title{
Molecular analysis of a synthetic tetracycline-binding riboswitch
}

\author{
SHANE HANSON, GESINE BAUER, BARBARA FINK, and BEATRIX SUESS \\ Lehrstuhl für Mikrobiologie, Friedrich-Alexander-Universität Erlangen-Nürnberg, 91058 Erlangen, Germany
}

\begin{abstract}
Riboswitches are newly discovered regulatory elements that consist solely of RNA, sense their ligand in a preformed binding pocket, and perform a conformational switch in response to ligand binding, resulting in altered gene expression. Regulation by a tetracycline (tc)-binding aptamer when inserted into the $5^{\prime}$ untranslated region (UTR) of a reporter gene exhibits all characteristics of a riboswitch. Chemical and enzymatic probing reveals that the aptamer consists of two stems, P1 and P2, which are already present in the absence of tc and form the scaffold of the aptamer. They are separated by a bulge B1-2 and an opposing stem-loop (P3-L3). Tc-dependent changes in the probing pattern only appear in the upper part of the bulge B1-2 (nucleotides 9-13) and the loop L3. Saturating mutagenesis corroborates the involvement of these two regions in regulation. Structural probing of the mutant A55U, which contains a single-nucleotide exchange in loop L3 results in a changed probing pattern of the loop, but also of the opposing bulge B1-2. This denotes that both regions cooperate and form a composite binding pocket. Thus, our model for aptamer-mediated translational regulation is that the ligand-free aptamer has only marginal influence on translational initiation. Tc then leads to an intramolecular connection in a pseudoknot-like manner and turns the aptamer into its inhibitory form. This represents a new mechanism for riboswitch action clearly distinguished from currently known naturally occurring riboswitches, which function by sequestration of the ribosomal binding site, transcriptional attenuation, and ribozyme-mediated degradation.
\end{abstract}

Keywords: tetracycline; aptamer; riboswitch; structural probing; saturating mutagenesis

\section{INTRODUCTION}

The importance of RNA for gene regulation is essentially due to its conformational flexibility and functional versatility. Recently, novel regulatory elements controlling a wide set of basic metabolic pathways in prokaryotes have been reported (for review, see Winkler and Breaker 2003; Nudler and Mironov 2004; Soukup and Soukup 2004). These molecular switches, called riboswitches, consist solely of RNA, they sense their ligand in a preformed binding pocket, and undergo restructuring upon metabolite binding. This affects gene expression by either causing transcription attenuation (Mironov et al. 2002; Winkler and Breaker 2002), inhibition of translation initiation (Nahvi et al. 2002; Winkler et al. 2002 b) or ribozyme-mediated mRNA degradation (Winkler et al. 2004). These riboswitches function in the absence of any sensor protein. Their novelty is that now RNA accom-

Reprint requests to: Beatrix Suess, Lehrstuhl für Mikrobiologie, Friedrich-Alexander-Universität Erlangen-Nürnberg, Staudtstrasse 5, 91058 Erlangen, Germany; e-mail: bsuess@biologie.uni-erlangen.de; fax: 49-9131852-80-82.

Article and publication are at http://www.rnajournal.org/cgi/doi/ 10.1261/rna.7251305. plishes both sensor and regulator functions and thereby integrates the tasks formerly performed by a protein and an RNA component.

Recent studies using specific RNA aptamers to design small molecule-dependent synthetic riboswitches have opened new perspectives in the field of translational control. Aptamers are RNA molecules selected by SELEX in vitro to bind specifically to their target molecules (Ellington and Szostak 1990; Tuerk and Gold 1990). They adopt a unique conformation upon ligand binding, wherein the ligand becomes an integral part of the complex (Patel et al. 1997; Hermann and Patel 2000). Naturally occurring riboswitches are therefore comparable to these in vitro-selected aptamers by both exploiting the remarkable structural and functional versatility of RNA and by exhibiting the outstanding binding affinity and specificity. Thus, in principle, RNA aptamers have the potential to act as synthetic riboswitches by having aptamer-ligand complex formation interfere with initial stages of translation when it is inserted into the 5'UTR of a reporter mRNA (Werstuck and Green 1998).

We have identified a tc-binding aptamer capable of controlling translation in Saccharomyces cerevisiae by direct 
RNA-ligand interaction (Suess et al. 2003). The aptamer leads to up to 15 -fold reduction of reporter activity in vivo when inserted directly in front of the start codon (Hanson et al. 2003). The analysis of ribosomal distribution of in vitro-translated aptamer-containing RNA using sucrose gradients has shown that the tc-bound aptamer interferes with the formation of the $80 \mathrm{~S}$ ribosome, probably by blocking scanning (Hanson et al. 2003). But, the aptamer is also active when placed behind the cap structure. Here, aptamer-tc complex formation prevents binding of the small ribosomal subunit to the cap structure.

Thus, the tc aptamer shows all characteristics of a riboswitch; it binds its ligand with high affinity and specificity by direct ligand-RNA interactions, and the resulting complex then effects gene expression. The aptamer is not dependent on the insertion site within the untranslated region. In addition, the aptamer is of suitable size and responds in a dose-dependent and reversible manner to a small molecule that is not a cellular metabolite (Suess et al. 2003). This makes the tc aptamer not just an excellent molecular switch for conditional gene expression, but also a suitable model system to elucidate molecular and structural mechanisms underlying these novel regulatory elements. Hence, we combined structural and enzymatic probing with saturation mutagenesis in the absence and presence of tc to define the secondary structure of the aptamer inserted within the $5^{\prime}$ UTR directly in front of the start codon, and identified regions involved in ligand binding and occurring conformational changes. We ascertain that the aptamer forms a composite binding pocket. The ligand then connects the two distinct regions of the aptamer by a pseudoknot-like intramolecular linkage, which leads to the inhibition competent conformation. This reveals a novel mechanism for riboswitches differing from naturally occurring variants which are based on transcriptional attenuation, sequestration of the ribosomal binding site, and ribozyme-mediated degradation.

\section{RESULTS AND DISCUSSION}

\section{Probing secondary structure of the tc aptamer in its mRNA context}

We probed the secondary structure of the tc-binding aptamer with structure- specific nucleases. RNase V1 cleaves double-stranded RNA or stacked nucleotides, while S1 cleaves single-stranded RNA (Ehresmann et al. 1987; Knapp 1989). We used a 150-nucleotide long RNA fragment carrying the tc aptamer in its mRNA context directly in front of the start codon (complete 5'UTR and the first 48 nucleotides of the GFPencoding reading frame). ${ }^{32} \mathrm{P}$-labeled RNA was treated with the respective nucleases, and the resulting fragments were sized by electrophoresis on a denaturing polyacrylamide gel. The fragmentation pattern is shown in Figure 1A. The results of the enzymatic cleavage are summarized schematically onto the secondary structure of the tc aptamer calculated by the mfold Web server (version 3.1, http://www. bioinfo.rpi.edu/applications/mfold) (Zuker 2003; Fig. 2A).

Double-strand specific cuts at the positions G1, C3-A6, U64-G66, and C69 suggest that the stem P1 is formed in solution but extended to include the base pair A6-U64. The

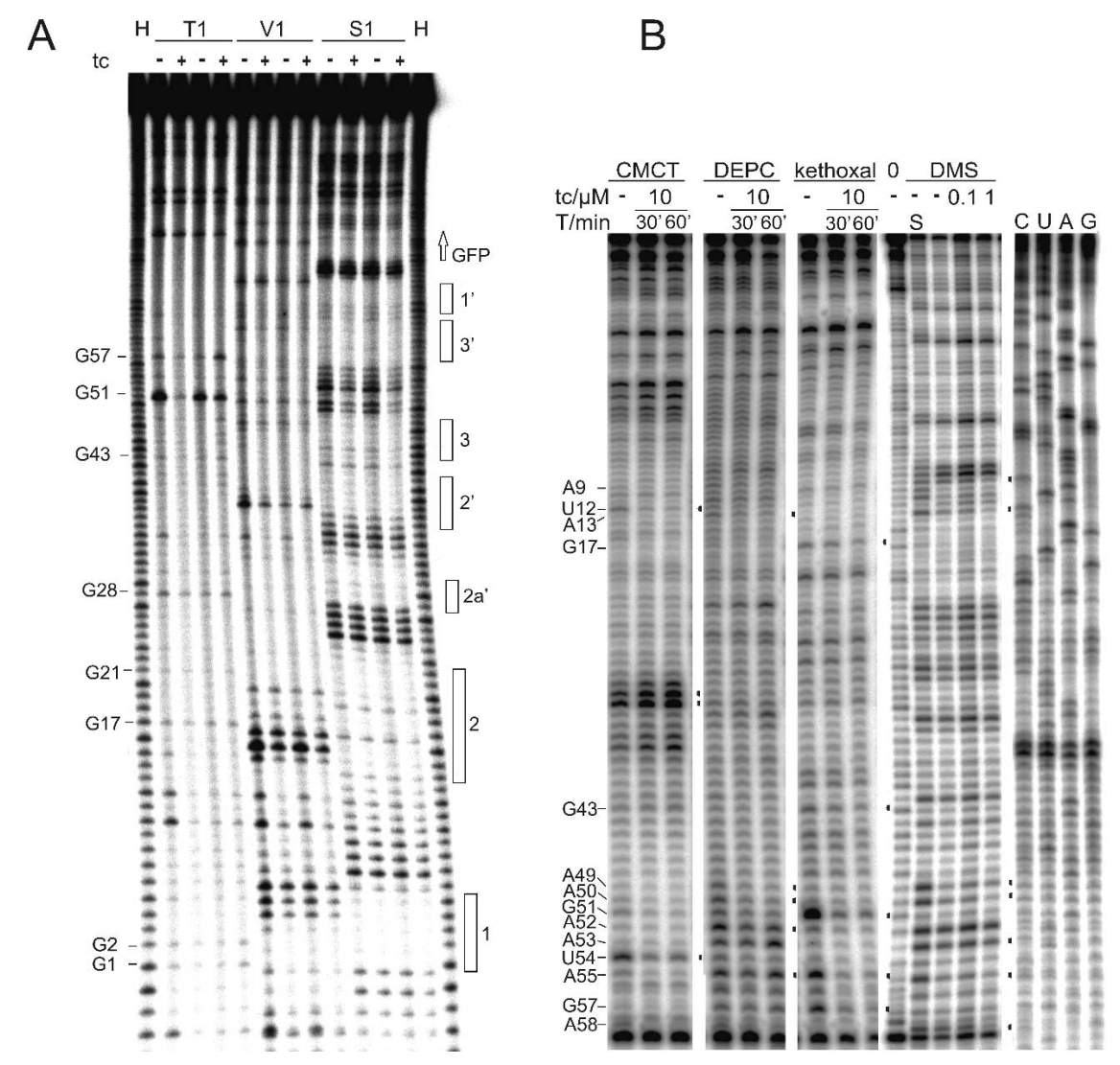

FIGURE 1. Enzymatic and chemical probing of the tc-binding aptamer. (A) Limited digestion was performed using a 150-nucleotide-long RNA containing the aptamer in its mRNA context. Probing was carried out using RNase T1 (0.5 and $0.25 \mathrm{U})$, RNase V1 (0.005 and $0.001 \mathrm{U})$, and S1 nuclease ( 1 and $0.5 \mathrm{U})$ in the absence $(-)$ and presence $(+)$ of $10 \mu \mathrm{M}$ tc. The two left-hand lanes of each nuclease probing correspond to the respective higher enzyme concentration. Alkaline hydrolysis of the RNA is denoted by H. G residues probed with RNase T1 are marked at left, and stem regions proposed by secondary structure prediction are denoted at the right side of the plot with open bars. $(B)$ Chemical modifications were performed in the absence and presence of tc and monitored by primer extension reaction. Untreated RNA is marked with an 0 . The incubation time $(\mathrm{T})$ and the concentration of tc is given above the figure. $(\mathrm{C}, \mathrm{U}, \mathrm{A}, \mathrm{G})$ Sequencing lanes. (S) DMS modification carried out under semidenaturing conditions in the presence of EDTA. Nucleotide positions with occurring tc-dependent changes in the probing pattern are denoted and marked with arrowheads at the left side of the plot. 
A

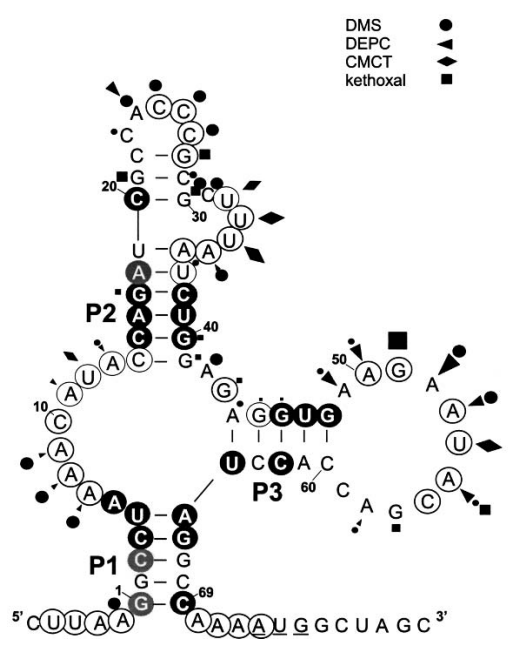

B

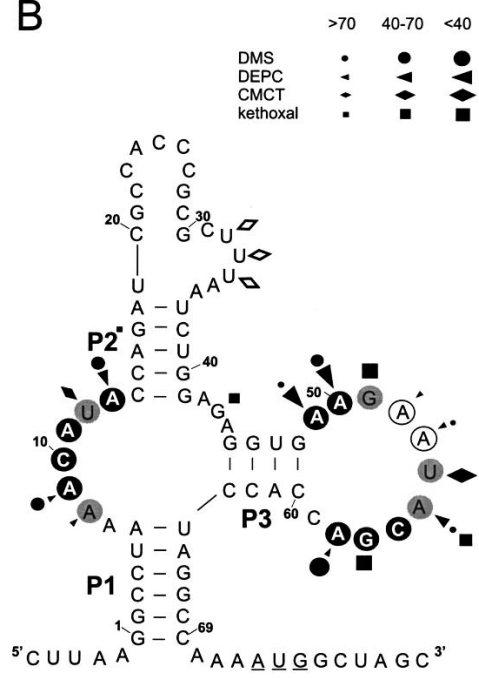

FIGURE 2. Summary of the secondary structure analyses and tc-dependent changes of the tc-binding aptamer. (A) RNA secondary structure prediction was conducted at the mfold Web server (version 3.1; Zuker 2003). The AUG start codon of the gfp reading frame is underlined. Nucleotide positions with double-strand specific V1 cuts are highlighted with filled circles, the intensity of the filling correlates with the strongness of the V1 signal. Positions amenable to S1-mediated single-strand cuts are highlighted with open circles. Positions that were modified by chemical probes are marked with symbols (DMS, circle; DEPC, arrowhead; kethoxal, square; CMCT, diamond). The size of the symbols correlates with the intensity of the signal; the largest symbols correspond to the highest level of modification. (B) Positions with tc-dependent changes of the chemical modification pattern are marked with symbols (DMS, circle; DEPC, arrowhead; kethoxal, square; CMCT, diamond) onto the improved secondary structure derived from the structural probing analysis. The largest symbols correspond to the highest tc-dependent protection (a scaling in terms of degree reduction of signal intensity is given top, right of the blot). Open and closed symbols indicate an increase and decrease, respectively, in signal strength. Nucleotides highlighted with circles were saturating mutagenized. Resulting mutants were analyzed in vivo for their ability for tc-dependent regulation of gene expression when inserted into the $5^{\prime}$ UTR of a reporter mRNA. Positions highlighted in black are completely intolerant toward mutation, gray circles indicate positions at which mutations lead to reduced regulatory activity, and open circles indicate positions at which all nucleotide exchanges do not influence regulation.

lower part of P1 is less susceptible to RNase V1. V1 cuts at positions C15-A18 and C38-G40 agree with the existence of the lower part of stem 2. However, the lack of V1 cuts, combined with extended single-stranded regions between the nucleotides (nt) C25 and U37 indicate that the predicted P2' stem-loop structure is not reliably formed. V1 cuts at G46-G48 and C62 support formation of P3. Further S1 cleavages are consistent with all predicted single-strand regions as follows: the bulge $\mathrm{B} 1-2$ (A7-C14), the joining region J2-3 (G43), and the loop L3 (A50, G51, A53-C56).

The accessibility of RNA toward modifications by basespecific chemical reagents allows conclusions about the involvement of specific nucleotides in base pairing or tertiary interactions (Ehresmann et al. 1987). DMS (dimethylsulphate) methylates position N-1 of A, CMCT (1-cyclohexyl3-[2-morpholinoethyl] carbodiimidemetho-p-toluenesulfonate) modifies position $\mathrm{N}-3$ of $\mathrm{U}$ and kethoxal ( $\beta$-ethoxy$\alpha$-ketobutyraldehyde) reacts with $\mathrm{G}$, generating a cyclic adduct between $\mathrm{N}-1$ and $\mathrm{N}-2$. Position N-7 of A involved in Hoogsteen or reverse-Hoogsteen interactions are probed by
DEPC. The RNA fragments were treated with DMS, CMCT, kethoxal, and DEPC and subjected to a primer extension reaction using a ${ }^{32} \mathrm{P}$-labeled primer. A control of unmodified RNA was run in parallel to discriminate between stops of the reverse transcriptase specifically induced by modification and pausing due to secondary structures or spontaneous cleavages. The modification pattern is shown in Figure 1B. Bases accessible to the respective chemicals are marked with symbols in the secondary structure in Figure 2A.

None of the proposed stem regions show signals caused by base modification. The failure of DMS modification at position A6 and a signal at position A44 caused by DMS methylation support the formation of the base pair A6-U64 of stem P1 instead of A44-U46 of stem P3. Strong signals at G21, G28, C29, and G30 indicate that the upper part of P2 does not form, as it was already suggested by nuclease digestion. A refined secondary structure, which includes all new insights from structural probing, is shown in Figure 2B.

Nearly all bases located in the proposed single-stranded regions B1-2, J23 , and $\mathrm{L} 3$ are accessible to chemical modification, however, to different degrees. The DMS and CMCT signals at positions 11,12 , and 13 are less intense than signals of the adenines 7,8 , and 9 in the lower half of bulge B1-2. This is in agreement with the gradual decrease in signal strength for the S1 cuts in this bulge. The reduced accessibility indicates an involvement of the upper part of the bulge in tertiary interaction. Single V1 cuts at the positions 10 and 12 confirm these tertiary interactions. A similar effect is observed for loop L3. We observe a better accessibility for nt $51-55$ than for $49,50,57$, or 58 (see Fig. 1A). These tertiary interactions occur in the presence of $\mathrm{Mg}^{2+}$. Whereas all stem regions are already formed under semidenaturing conditions (Fig. 1B, second lane [S] of the DMS probing), the differences in the accessibility within the single-stranded region B1-2 and L3 first appear in the presence of $\mathrm{Mg}^{2+}$ (compare the second and third lane of the DMS probing). Interestingly, we observe a signal caused by kethoxal for the adenine at position 55 . This may be due to conformational constraints leading to a local $\mathrm{pKa}$ shift of the adenine, which would then allow a cyclic addition of kethoxal.

Taken together, the results of the structural probing analyses are nearly consistent with the proposed secondary 
structure of the aptamer located in its mRNA context. All stem regions are already formed in the absence of the ligand. This explains the partial decrease of translation efficiency in vivo when the aptamer is inserted in the nontranslated region of a reporter gene (Hanson et al. 2003; Suess et al. 2003). Parts of bulge B1-2 and loop L3 are single-stranded, but become involved in tertiary interaction after the addition of $\mathrm{Mg}^{2+}$.

\section{Bulge B1-2 and Loop L3 are involved in tc binding}

Our next concern was to assess regions involved in tc binding. Therefore, we repeated the structural analyses in the presence of the ligand tc. RNA was incubated with 0.1-10 $\mu \mathrm{M}$ tc and subsequently subjected to enzymatic and chemical modification analyses as described above. The probing patterns are shown in Figure 1. Positions exhibiting tcdependent changes in the probing pattern were quantified. The data are summarized in Table 1 and marked with symbols upon an improved illustration of the secondary structure incorporating the structural probing data (Fig. 2B). Thereby, the size of the symbols corresponds to the degree of signal change.

The addition of tc does not effect the overall secondary structure, because nearly all signals observed by enzymatic and chemical probing exist also in the presence of tc. We observe a strong decrease of the probing signal at nucleotide positions A9, U12, and A13 located in the upper half of bulge B1-2, for which an involvement in tertiary interaction had already been proposed. Furthermore, a drastic decrease is observed for nearly all nucleotides of the loop L3 (Table 1; Fig. 2B). The exceptions are A52 and A53 with only marginal signal reduction. In addition, tc-dependent protection of A50, G51, U54, A55, and C56 from S1 digestion supports the importance of the loop for ligand binding.

Tc binding to the aptamer was further investigated by hydroxyl radical probing. This method makes use of the ability of $\mathrm{Fe}^{2+}$ to replace the $\mathrm{Mg}^{2+}$-ion complexed with tc. After addition of hydrogen peroxide, $\mathrm{Fe}^{2+}$ generates shortlived, highly reactive hydroxyl radicals that can cleave proteins and nucleotides in proximity of bound tc (Ettner et al. 1993; McMurry et al. 2002; Bauer et al. 2004). In contrast to other probing methods, $\mathrm{Fe}^{2+}$-mediated hydroxyl radicals cleave nucleic acids with little or no sequence specificity (Tullius et al. 1987; Balasubramanian et al. 1998), and a significant secondary structure preference has not been observed in radical-induced cleavage of single- and doublestranded forms of RNA and DNA (Celander and Cech 1990).

A 71-nucleotide-long RNA fragment containing the tcbinding aptamer was probed with $250 \mu \mathrm{M} \mathrm{Fe}^{2+}, 2.5 \mathrm{mM}$ sodium ascorbate, and $2.5 \mathrm{mM} \mathrm{H}_{2} \mathrm{O}_{2}$ in the presence of $1-100 \mu \mathrm{M} \mathrm{tc}$, resulting in one tc-dependent signal at position A55 (Fig. 3). Beside this signal, no additional cleavage sites were obtained. The $\mathrm{Mg}^{2+}$-competition experiment shows decreasing signal intensities for increasing amounts
TABLE 1. Quantification of tc-dependent changes of the chemical probing analysis

\begin{tabular}{|c|c|c|c|}
\hline & & Wild-type aptamer & $\begin{array}{c}\text { Mutant aptamer } \\
\text { A55U }\end{array}$ \\
\hline $\begin{array}{l}\text { Aptamer } \\
\text { position }\end{array}$ & $\begin{array}{l}\text { Chemical } \\
\text { probe }\end{array}$ & $\begin{array}{l}\text { Normalized } \\
\text { intensity } / \%\end{array}$ & $\begin{array}{l}\text { Normalized } \\
\text { intensity } / \%\end{array}$ \\
\hline A9 & DMS & $36.5 \pm 4.9$ & $131 \pm 16.0$ \\
\hline A13 & DMS & $38.2 \pm 3.2$ & $68.1 \pm 11.2$ \\
\hline A49 & DMS & $94.9 \pm 0.5$ & $72.3 \pm 9.2$ \\
\hline A50 & DMS & $36.8 \pm 2.8$ & $26.5 \pm 3.3$ \\
\hline A53 & DMS & $62.7 \pm 3.0$ & $79.4 \pm 10.5$ \\
\hline A55 & DMS & $60.5 \pm 6.2$ & \\
\hline A58 & DMS & $38.0 \pm 6.5$ & $38.4 \pm 6.0$ \\
\hline A8 & DEPC & $83.2 \pm 2.5$ & $90.4 \pm 5.7$ \\
\hline A9 & DEPC & $77.6 \pm 1.4$ & $110 \pm 5.8$ \\
\hline A13 & DEPC & $56.3 \pm 2.2$ & $84.3 \pm 3.6$ \\
\hline A49 & DEPC & $28.2 \pm 2.1$ & $40.3 \pm 3.2$ \\
\hline A50 & DEPC & $31.6 \pm 2.5$ & $42.4 \pm 2.3$ \\
\hline A52 & DEPC & $65.2 \pm 3.3$ & $63.7 \pm 2.3$ \\
\hline A53 & DEPC & $91.7 \pm 5.9$ & $115 \pm 7.1$ \\
\hline A55 & DEPC & $68.5 \pm 4.1$ & \\
\hline A58 & DEPC & $73.5 \pm 3.3$ & $63.4 \pm 3.1$ \\
\hline U12 & СМCT & $46.0 \pm 2.8$ & $75.4 \pm 3.0$ \\
\hline U32 & СMCT & $192 \pm 3.4$ & $120 \pm 5.7$ \\
\hline U33 & СMCT & $196 \pm 4.9$ & $123 \pm 5.7$ \\
\hline U34 & СMCT & $187 \pm 6.3$ & $115 \pm 7.8$ \\
\hline U54 & СMCT & $18.9 \pm 3.1$ & $95.5 \pm 77$ \\
\hline U55 & СMCT & & $105 \pm 5.2$ \\
\hline G43 & kethoxal & $47.6 \pm 5.2$ & $39.9 \pm 4.6$ \\
\hline G51 & kethoxal & $13.6 \pm 2.3$ & $30.5 \pm 3.3$ \\
\hline G57 & kethoxal & $19.8 \pm 2.1$ & $17.9 \pm 1.5$ \\
\hline
\end{tabular}

Quantification of tc-dependent changes in the chemical probing pattern. Chemical modifications of the tc-binding aptamer and the mutant variant $\mathrm{A} 55 \mathrm{U}$ were carried out for $20 \mathrm{~min}$ (DMS) and 30 $\min (\mathrm{CMCT}$, kethoxal, DEPC) in the absence and presence of $1 \mu \mathrm{M}$ tc. The signals were quantified in a phosphoimager, and intensities were normalized after correction for background. The signals in the absence of tc were taken as $100 \%$.

of $\mathrm{Mg}^{2+}$, indicating that $\mathrm{Fe}^{2+}$ and $\mathrm{Mg}^{2+}$ might interact with overlapping sites. As the aptamer alone shows no conformational changes upon addition of increasing amounts of $\mathrm{Mg}^{2+}$ (C. Berens, pers. comm.), this indicates a direct competition between $\mathrm{Fe}^{2+}$ and $\mathrm{Mg}^{2+}$. Thus, the pronounced cleavage signal at position A55 provides additional evidence for the importance of loop L3 in tc binding and is also in nice agreement with lead cleavage data that indicated an involvement of bulge B1-2 and the loop L3 in tc binding (Berens et al. 2001).

The observed tc-dependent changes are restricted mainly to bulge B1-2 and loop L3 of the aptamer as summarized in Figure 2B. The stems P1 and P2 do not interact with tc and may only be of structural importance. This conclusion is supported by in vivo data obtained previously. Both stems have been varied in length and sequence without loss of regulation (Hanson et al. 2003; Suess et al. 2003). Hence, we propose that $\mathrm{P} 1$ and $\mathrm{P} 2$ may be responsible only for maintaining the scaffold of the aptamer structure, whereas bulge 


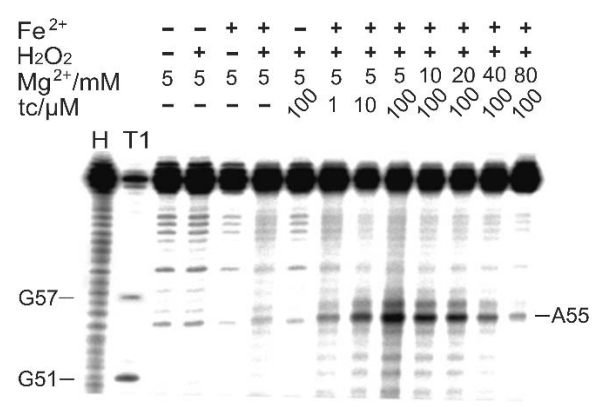

FIGURE 3. $\mathrm{Fe}^{2+}$-mediated hydroxyl radical cleavage reaction of the tc-binding aptamer. Cleavage was performed using the 71-nucleotidelong aptamer RNA. Probing was carried out with increasing amounts of tc in the presence of $\mathrm{Fe}^{2+}$ and $\mathrm{NaOAsc} / \mathrm{H}_{2} \mathrm{O}_{2}$. For $\mathrm{Mg}^{2+}$ competition, the RNA was treated with $\mathrm{Fe}^{2+} / \mathrm{H}_{2} \mathrm{O}_{2}$ and increasing amounts of $\mathrm{Mg}^{2+}$ in the presence of $100 \mu \mathrm{M}$ tc. (H) Alkaline hydrolysis; (T1) RNase $\mathrm{T} 1$ sequencing ladder.

B1-2 and loop L3 are responsible for the formation of the tc-binding pocket.

\section{Investigating structure-function relationships by saturating mutagenesis}

Saturating mutagenesis was performed on the basis of chemical and enzymatic protection data to identify base positions important for the regulatory activity in vivo. Aptamers were mutagenized at the nt $8-13$ and $49-58$ by PCR mutagenesis and inserted directly upstream of the start codon of a constitutively expressed $g f p$ gene (Suess et al. 2003). The resulting plasmids were transformed into $S$. cerevisiae, and GFP fluorescence was determined in the absence and presence of $100 \mu \mathrm{M}$ tc. The data are summarized in Table 2 and displayed as highlighted positions in Figure 2B.

Mutations at the positions 9-11 and 13 in B1 and 49, 50, and 56-58 in L3 result in a complete loss of regulation, irrespective of the nucleotide exchange introduced. This agrees nicely with the in vitro results that show strong tcdependent changes and an involvement of these positions in binding-pocket formation. Mutations at positions 8, 12, 51, 54 , and 55 are tolerated, but lead to reduced regulation. Thus, these positions participate in ligand binding, maybe not by direct interaction, but by an involvement in bindingpocket formation, and are therefore significant for tight binding of tc. All nucleotide exchanges in the probing pattern at positions 52 and 53, which were proposed to be not involved in tertiary interactions or tc binding, show regulatory properties like wild type. Mutations U10, G13, A51, U50, G55, U56, and U57 are not amenable to analysis due to strong reduction of GFP expression already in the ab-

TABLE 2. Regulatory properties of aptamer mutants in vivo

\begin{tabular}{|c|c|c|c|c|c|c|c|c|c|c|c|c|}
\hline \multirow{2}{*}{$\begin{array}{l}\text { Position } \\
\text { Exchange to }\end{array}$} & \multicolumn{3}{|c|}{ Relative fluorescence in \% } & \multicolumn{3}{|c|}{ Relative fluorescence in \% } & \multicolumn{3}{|c|}{ Relative fluorescence in \% } & \multicolumn{3}{|c|}{ Relative fluorescence in \% } \\
\hline & $-\mathrm{tc}$ & $\begin{array}{l}100 \mu \mathrm{M} \text { tc } \\
\boldsymbol{x}=\boldsymbol{A}\end{array}$ & $\mathrm{F}$ & $-\mathrm{tc}$ & $\begin{array}{l}100 \mu \mathrm{M} \text { tc } \\
\boldsymbol{x}=\boldsymbol{C}\end{array}$ & $\mathrm{F}$ & $-\mathrm{tc}$ & $\begin{array}{l}100 \mu \mathrm{M} \text { tc } \\
\boldsymbol{x}=\boldsymbol{G}\end{array}$ & $\mathrm{F}$ & $-\mathrm{tc}$ & $\begin{array}{l}100 \mu \mathrm{M} \text { tc } \\
\boldsymbol{x}=\boldsymbol{U}\end{array}$ & $\mathrm{F}$ \\
\hline wild type & $100 \pm 0$ & $17 \pm 4.1$ & 5.8 & & & & & & & & & \\
\hline $\mathrm{A} 8 \mathrm{x}$ & & & & $128 \pm 9.2$ & $45 \pm 5.1$ & 2.8 & $119 \pm 11$ & $39 \pm 1.9$ & 3.1 & $129 \pm 9.6$ & $62 \pm 9.0$ & 2.1 \\
\hline A9x & & & & $128 \pm 12.8$ & $114 \pm 4.6$ & 1.1 & $132 \pm 12$ & $134 \pm 5.4$ & 1.0 & $147 \pm 9.1$ & $149 \pm 6.3$ & 1.0 \\
\hline $\mathrm{C} 10 \mathrm{x}$ & $99 \pm 9.3$ & $104 \pm 11$ & 0.9 & & & & $144 \pm 10$ & $145 \pm 6.8$ & 1.0 & $3.1 \pm 2.5$ & $3.5 \pm 2.9$ & 0.9 \\
\hline $\mathrm{A} 11 \mathrm{x}$ & & & & $103 \pm 8.2$ & $123 \pm 5.7$ & 0.9 & $106 \pm 9.8$ & $107 \pm 11$ & 1.0 & $145 \pm 6.9$ & $137 \pm 6.5$ & 1.1 \\
\hline U12x & $87 \pm 6.6$ & $33 \pm 6.0$ & 2.6 & $92 \pm 14.4$ & $102 \pm 7.3$ & 0.9 & $125 \pm 12$ & $66 \pm 5.0$ & 1.9 & & & \\
\hline A13x & & & & $90 \pm 14.2$ & $103 \pm 9.2$ & 0.9 & $6.5 \pm 1.4$ & $7.5 \pm 2.6$ & $0.9^{\mathrm{a}}$ & $90 \pm 7.0$ & $97 \pm 8.0$ & 0.9 \\
\hline A49x & & & & $98 \pm 9.1$ & $96 \pm 7.0$ & 1.0 & $54 \pm 6.6$ & $56 \pm 16$ & 1.0 & $104 \pm 8.5$ & $92 \pm 11$ & 1.1 \\
\hline A50x & & & & $83 \pm 1.1$ & $79 \pm 7.0$ & 1.0 & $79 \pm 0.1$ & $84 \pm 13$ & 0.9 & $8.9 \pm 0.6$ & $9.7 \pm 1.1$ & $0.9^{\mathrm{a}}$ \\
\hline G51x & $7 \pm 3.3$ & $5.5 \pm 3.5$ & 1.3 & $114 \pm 8.7$ & $37 \pm 0.7$ & 3.1 & & & & $94 \pm 8.1$ & $31 \pm 7.9$ & 3.0 \\
\hline A52x & & & & $76 \pm 0.6$ & $15 \pm 1.5$ & 5.1 & $80 \pm 14$ & $14 \pm 6.4$ & 5.7 & $105 \pm 11$ & $17 \pm 5.9$ & 6.0 \\
\hline A53x & & & & $97 \pm 8.7$ & $15 \pm 4.7$ & 6.5 & $100 \pm 13$ & $24 \pm 3.8$ & 4.1 & $88 \pm 11$ & $13 \pm 4.5$ & 6.4 \\
\hline U54x & $101 \pm 11$ & $18 \pm 3.9$ & 5.4 & $92 \pm 3.0$ & $23 \pm 2.3$ & 4.0 & $81 \pm 11$ & $24 \pm 7.4$ & 3.3 & & & \\
\hline A55x & & & & $63 \pm 3.5$ & $19 \pm 0.1$ & 3.3 & $79 \pm 10$ & $26 \pm 3.9$ & $2.9^{\mathrm{b}}$ & $88 \pm 7.1$ & $34 \pm 11$ & 2.6 \\
\hline C56x & $111 \pm 12$ & $101 \pm 12$ & 1.1 & & & & $120 \pm 14$ & $128 \pm 8.4$ & 0.9 & $40 \pm 2.9$ & $36 \pm 3.9$ & $1.1^{\mathrm{a}}$ \\
\hline G57x & $115 \pm 16$ & $118 \pm 8.6$ & 1.0 & $81 \pm 9.9$ & $80 \pm 7.3$ & 1.0 & & & & $1.8 \pm 2.4$ & $1.7 \pm 2.1$ & 1.1 \\
\hline A58x & & & & $73 \pm 8.4$ & $77 \pm 0.2$ & 1.0 & $85 \pm 12$ & $85 \pm 9.4$ & 1.0 & $97 \pm 3.8$ & $101 \pm 11$ & 1.0 \\
\hline \multicolumn{13}{|l|}{ mutant A55U } \\
\hline A53x & & & & $33 \pm 2.3$ & $27 \pm 1.8$ & 1.2 & $62 \pm 3.3$ & $53 \pm 8.2$ & 1.2 & $62 \pm 4.4$ & $42 \pm 2.1$ & 1.4 \\
\hline
\end{tabular}

Regulatory properties of aptamer mutants with nucleotide exchanges at positions proposed to be involved in tc binding. Fluorescence was measured after $48 \mathrm{~h}$ incubation in the absence (column 2, 5, 8, and 11, -tc) or presence (column 3, 6, 9, and 12) of $100 \mu \mathrm{M} \mathrm{tc}$. The fluorescence of the constitutively expressed GFP gene with the wild-type aptamer in the absence of tc was set to $100 \%$. Columns 4, 7, 10, and 13 (marked with F) show the efficiency of regulation given as the ratios of relative fluorescence values without and with tc.

aMutations lead to the introduction of a premature start codon in the 5'UTR.

${ }^{b}$ Measured as double-mutant C53G55 to avoid the formation of a premature start codon. 
sence of tc. For G13, U50, G55, and U56, this is caused by the introduction of a premature start codon in the $5^{\prime} \mathrm{UTR}$.

Thus, the in vivo results show that several positions of both the bulge B1-2 and the loop L3 are not at all exchangeable, and thereby support the assumption that both regions participate in the formation of the ligand-binding pocket.

\section{Aptamer mutant A55U suppose the formation of a composite binding site}

Structural probing and mutational analysis revealed that the binding pocket is composed of two parts. We now ask whether each part can bind one single molecule tc, or do both regions that are separated in the secondary structure, and contribute to interaction by forming a composite binding pocket. To elucidate this, we analyzed an aptamer mutant, A55U, which is regulatory active, but with reduced efficiency (Suess et al. 2003). We performed enzymatic and chemical probing assays as described above for the wild type. The fragmentation and modification patterns were similar to that of the wild-type aptamer (data not shown), indicating that there are no overall changes in the secondary structure. We have quantified all tc-dependent changes. The data are included in Table 1. Segments of the gels with prominent changes in the probing pattern are shown in Figure 4. Astonishingly, the nucleotide exchange at position 55 , which is located in loop L3, affects the probing pattern of bulge B1-2. We observe an increase of the DMS signal at A9 and a slight reduction at the U12 and A13, whereas the wild-type aptamer shows a strong reduction at all three positions (Table 1; Fig. 4). These data support the hypothesis that bulge B1-2 and loop L3 interact with each other and participate in formation of a composite binding pocket for tc.

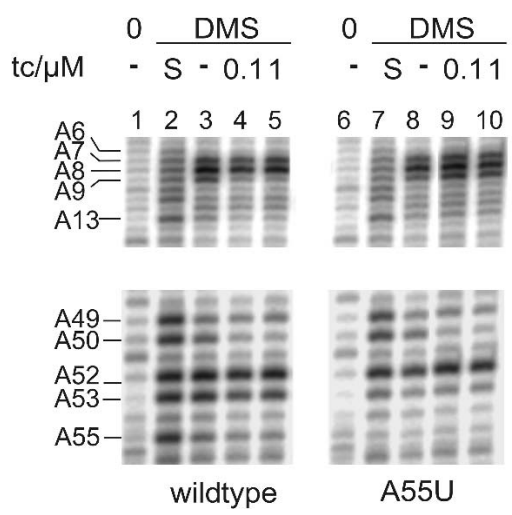

FIGURE 4. Comparative analyses of the DMS modification pattern of tc-binding aptamer and the aptamer mutant A55U. DMS modification of a 150-nucleotide-long RNA fragment containing the aptamer (wildtype or A55U mutant) in its mRNA context were performed in the absence and presence of tc and monitored by primer extension reaction. Untreated RNA is marked with 0 . The concentration of tc is given above the plot. (S) DMS modification carried out under semidenaturing conditions in the presence of EDTA. Positions with tcdependent changes in the probing pattern are denoted at left.

\section{A55 participates in tc binding}

The comparison of wild-type with the A55U mutant shows that the strong tc-dependent decrease at the wild-type adenine of position 55 is now shifted to the adenine at position 53, a position which is completely uninfluenced in the wild-type aptamer. This presumes that adenine at position 55 may be directly participating in tc binding. If the adenine is then mutated to a uridine, as in the case of $\mathrm{A} 55 \mathrm{U}$, the adenine at position 53 appears to take on the task of position 55. To test this, we mutagenized position 53 of the mutant. The data are included in Table 2. Whereas in the wild-type aptamer, position 53 is not sensitive to mutations, in the mutant $\mathrm{A} 55 \mathrm{U}$ context, a complete loss of regulation is observed, irrespective of the nucleotide exchange introduced. This shows that the adenine at position 53 is essential when the wild-type adenine at position 55 is mutated and is able to functionally suppress the defect caused by mutation of A55.

\section{Intramolecular linkage-the mechanistic basis for tc activity?}

The crystal structure of the small ribosomal subunit of Thermus thermophilus shows two main binding sites for the antibiotic tc (Brodersen et al. 2000; Pioletti et al. 2001). Both sites are formed by at least two separate parts of the 16S rRNA, both are composed of an irregular part of a helix that forms a pocket-like structure and a second part that shapes a lid to close the pocket. The primary tc-binding site is formed by a distorted minor groove of helix h34. The stacked nt 1196-1200 and 1056-1053 form a clamp that holds the tc molecule by hydrophobic interactions and hydrogen bonding. Residues 965 and 966 from the h31 stemloop make contacts to tc from the opposite side and close the binding pocket. We find a similar assembly for the secondary binding site (Brodersen 2000, site 2; Pioletti 2001, site 5), which is composed of h27 and nt of h11 and h20. Thereby, the nt 894 and 895 , as well as 891-894 of h27, form a rather tight binding pocket mainly through stacking interactions. U244, C245 of h27, and G761 of h20 shape the lid. The sequence similarities between the primary binding pockets of the Escherichia coli 16S rRNA sequence and loop L3 of the aptamer are noticeable. The sequence of the ribosome (site 1: AAG [1196-1198] UACG [1056-1053]; site 2/5 AA [894,895] UACG [891-894]) fits well to the nucleotides AAG (49-51) and UACG (54-57) of loop L3 that we have determined to be important for tc binding in this study.

Thus, we propose that the loop L3 is responsible for the formation of a tc-binding pocket for tc generated by the nucleotides AAG (49-51) and UACGA (54-58). The tc molecule is probably buried deeply in this pocket and makes contact with multiple residues, explaining the strong chemical protection of nearly all nucleotides of the loop in 
the presence of tc and the strong sensitivity against nucleotide exchanges in vivo. The upper part of the bulge B1-2 would then form a lid, thereby trapping tc in the binding pocket.

This leads to our model of tc-aptamer-mediated translational regulation. The aptamer forms a scaffold by the stems $\mathrm{P} 1$ and P2 already in the absence of the ligand, which leads to a somewhat reduced reporter gene expression. The addition of tc then leads to the formation of the binding pocket. Multiple contacts of the tc to both the bulge B1-2 and loop L3 region mediate an intramolecular linkage within the aptamer in a pseudoknot-like manner. This complex is then able to efficiently interfere with the ribosome, thereby inhibiting translational initiation.

This ligand-mediated intramolecular linkage forms the mechanistic basis of the synthetic tc riboswitch. Thus, it cannot be classified among the currently known natural riboswitches that are based on transcriptional attenuation, sequestration of the ribosomal binding site, or mRNA degradation, and consequently, represents a new class of riboswitches.

\section{MATERIALS AND METHODS}

\section{Preparation of RNA}

PCR amplification using pWHE601-AN32sh (wild-type aptamer) and -AN28sh (A55U mutant) (Suess et al. 2003) as template and the primers $\mathrm{T} 7$ in $\left(5^{\prime}\right.$-TCTAATACGACTCACTATAGGAGCATA CAATCAACTCC, the T7 recognition sequence is underlined) and GFP_rev (5'CAAGAATTGGGACAACTCC) was performed to obtain a 170-bp-long PCR product carrying the tc-binding aptamer in its mRNA context behind a T7 promoter. RNA transcription was carried out in $40 \mathrm{mM}$ Tris- $\mathrm{HCl}(\mathrm{pH} 7.5), 26 \mathrm{mM} \mathrm{MgCl}_{2}, 3$ mM Spermidine, $20 \mathrm{mM}$ DTT, $2.5 \mathrm{mM}$ NTPs, $1 \mathrm{U}$ RNase inhibitor with $200 \mathrm{U}$ T7 RNA polymerase for $16 \mathrm{~h}$ at $37^{\circ} \mathrm{C}$, followed by DNase I treatment for $1 \mathrm{~h}$ at $37^{\circ} \mathrm{C}$. The RNA was purified on a $5 \%$ denaturing polyacrylamide gel (20:1) and eluted from gel slices by shaking for $6 \mathrm{~h}$ at room temperature in $10 \mathrm{mM}$ Tris- $\mathrm{HCl}(\mathrm{pH} 7.5)$, $0.1 \%$ SDS, 2 mM EDTA, and $250 \mathrm{mM}$ sodium acetate. After precipitation, the RNA was resuspended in chromatography grade water.

\section{RNA dephosphorylation and 5'end labeling}

Dephosphorylation of 100 pmol RNA was carried out in $0.1 \mathrm{M}$ Hepes-KOH ( $\mathrm{pH}$ 6.7) with $10 \mathrm{U}$ Calf Intestinal Phosphatase in a total volume of $20 \mu \mathrm{L}$ for $1 \mathrm{~h}$ at $37^{\circ} \mathrm{C}$. After phenolchloroform isoamylalcohol extraction and precipitation, $10 \mathrm{pmol}$ of RNA were $5^{\prime}$ end labeled with $30 \mu \mathrm{Ci}\left[\gamma_{-}{ }^{32} \mathrm{P}\right] \mathrm{ATP}$ and $10 \mathrm{U}$ T4 polynucleotide kinase in a total volume of $10 \mu \mathrm{L}$ for $30 \mathrm{~min}$ at $37^{\circ} \mathrm{C}$, then precipitated and gel purified.

\section{RNase protection assay}

A total of 100,000 of cpm 5' end-labeled RNA was incubated in 50 $\mathrm{mM}$ sodium acetate ( $\mathrm{pH} 4.5$ ), $280 \mathrm{mM} \mathrm{NaCl}, 4.5 \mathrm{mM} \mathrm{ZnSO}_{4}(\mathrm{~S} 1$ ), or $50 \mathrm{mM}$ Tris- $\mathrm{Cl}$ (pH 7.5) (T1 and V1) in the presence of $5 \mathrm{ng}$ of unlabeled yeast tRNAs for $2 \mathrm{~min}$ at $56^{\circ} \mathrm{C}$ and for $10 \mathrm{~min}$ at $37^{\circ} \mathrm{C}$. Afterward, $5 \mathrm{mM} \mathrm{MgCl}_{2}$ was added and the RNA was incubated at room temperature for $5 \mathrm{~min}$ without or with 1 or $10 \mu \mathrm{M} \mathrm{tc}$. A total of 1 or $0.5 \mathrm{U}$ of S1 nuclease (Promega), 0.25 or $0.5 \mathrm{U}$ of RNase T1 (Roche), or 0.001 or $0.005 \mathrm{U}$ of RNase V1 (Ambion) was then added and incubated for $5 \mathrm{~min}$ at room temperature. Alkaline hydrolysis was carried out in $50 \mathrm{mM}$ sodium carbonate buffer ( $\mathrm{pH}$ 9.0) for $3 \mathrm{~min}$ at $90^{\circ} \mathrm{C}$. All reactions were stopped by the addition of the equal volume of sample loading buffer (95\% formamid, $0.1 \%$ bromophenol blue, $20 \mathrm{mM}$ EDTA) and immediately putting on ice. Samples then were separated through $10 \%$ denaturing polyacrylamide gels at $40 \mathrm{~W}$ for $2 \mathrm{~h}$ and visualized by phosphorimagery.

\section{Chemical modification assays}

\section{Modification with DMS}

A total of 5 pmol of RNA was incubated in $80 \mathrm{mM}$ cacodylate buffer ( $\mathrm{pH} 7.5$ ) for $2 \mathrm{~min}$ at $56^{\circ} \mathrm{C}$ and for $10 \mathrm{~min}$ at $37^{\circ} \mathrm{C}$. Afterward, $5 \mathrm{mM} \mathrm{MgCl}_{2}$ was added, and the RNA was incubated for 5 $\mathrm{min}$ at room temperature without or with 1 or $10 \mu \mathrm{M}$ tc. Methylation was performed by incubation with $1 \mu \mathrm{L}$ DMS (1:8 dilution in $96 \%$ ethanol) for $20 \mathrm{~min}$ at room temperature. Reactions were stopped by addition of $1 \mu \mathrm{L} \beta$-mercaptoethanol (1:5 dilution in water). After precipitation, $5^{\prime}$ end-labeled primer was annealed and primer extension performed.

\section{Modification with DEPC, CMCT, and kethoxal}

A total of 5 pmol of RNA was incubated in $80 \mathrm{mM}$ cacodylate buffer ( $\mathrm{pH}$ 7.0) DEPC (Sigma), $50 \mathrm{mM}$ potassium borate buffer ( $\mathrm{pH}$ 8.0) CMCT (Sigma), or $50 \mathrm{mM}$ potassium borate buffer $(\mathrm{pH}$ 7.0) kethoxal (ICN) at $56^{\circ} \mathrm{C}$ for $2 \mathrm{~min}$ and at $37^{\circ} \mathrm{C}$ for $10 \mathrm{~min}$. Afterward, $5 \mathrm{mM} \mathrm{MgCl}$ was added, and the RNA was incubated for $5 \mathrm{~min}$ at room temperature without or with 1 or $10 \mu \mathrm{M}$ tc. A total of $10 \mu \mathrm{L}$ of DEPC, $10 \mu \mathrm{L}$ of CMCT $\left(42 \mathrm{mg} \mathrm{mL}^{-1}\right.$ stock in 50 $\mathrm{mM}$ potassium borate buffer at $\mathrm{pH} 8.0)$ or $5 \mu \mathrm{L}$ of kethoxal $(37 \mathrm{mg}$ $\mathrm{mL}^{-1}$ in $20 \%$ ethanol) were added. The DEPC-containing reaction mixtures were incubated at $37^{\circ} \mathrm{C}$ for 30 and 60 min with intermittent shaking. CMCT and kethoxal modifications were carried for 30 and $60 \mathrm{~min}$ at room temperature. Reactions were stopped by precipitation. 5 'end-labeled primer was annealed and primer extension performed.

\section{Primer extension}

Hybridization of modified RNA $(2.5 \mu \mathrm{L})$ and $1 \mu \mathrm{L}$ of 5 'end-labeled primer was carried out in $50 \mathrm{mM}$ Hepes- $\mathrm{KOH}(\mathrm{pH} 7.0)$ and 100 $\mathrm{mM} \mathrm{KCl}$ by heating the mixture for $1 \mathrm{~min}$ at $96^{\circ} \mathrm{C}$, followed by 15 min incubation at room temperature. Extension reaction was started in $50 \mathrm{mM}$ Tris- $\mathrm{HCl}$ ( $\mathrm{pH} 7.5$ ), $75 \mathrm{mM} \mathrm{KCl,} 3 \mathrm{mM} \mathrm{MgCl}_{2}$, $0.25 \mathrm{mM}$ dNTPs, $10 \mathrm{mM}$ DTT with $10 \mathrm{U}^{\circ}$ SuperscriptII RNaseH ${ }^{-}$ Reverse Transcriptase (Invitrogen) at $42^{\circ} \mathrm{C}$ for $50 \mathrm{~min}$. The reactions were stopped by alkaline hydrolysis of the RNA template. After precipitation, the DNA fragments were separated through $10 \%$ denaturing polyacrylamide gels at $40 \mathrm{~W}$ for $2 \mathrm{~h}$ and visualized by phosphorimagery. The sequencing reactions were carried out 
using the PCR templates with the T7 Sequencing kit (USB Corporation).

\section{$\mathrm{Fe}^{2+}$-mediated hydroxyl radical cleavage reactions}

A 71-nucleotide-long RNA fragment containing the tc-binding aptamer was generated by in vitro transcription using plasmid pSP $64 \mathrm{~B}_{\text {mono }}$ as a template. pSP64 $\mathrm{B}_{\text {mono }}$ encodes the wild-type aptamer stabilized by an additional G-C pair introduced in stem 1 under control of the T7-promotor. Homogenous 3' ends were obtained by introduction of a hammerhead ribozyme sequence. RNA dephosphorylation and 5'end labeling was performed as depicted above.

The hydroxyl radical cleavage was carried out similar as described before (Berens et al. 1998). A total of $1 \mu \mathrm{L}$ RNA (20 pmol cold RNA, spiked with $\sim 50,000 \mathrm{cpm}$ of $5^{\prime}\left[{ }^{32} \mathrm{P}\right]$-labeled RNA) was added to $1 \mu \mathrm{L}$ of $5 \times$ cleavage buffer $(5 \times$ CB: $125 \mathrm{mM}$ MOPS$\mathrm{KOH}$ (pH 7.0); $25 \mathrm{mM} \mathrm{MgCl}_{2} ; 500 \mathrm{mM} \mathrm{NaCl}$; the $5 \times \mathrm{CB}$ additionally included 5-500 $\mu \mathrm{M}$ tc for samples, in which the RNA was cleaved in the presence of tc) and incubated for $1 \mathrm{~min}$ at $60^{\circ} \mathrm{C}$, followed by $2 \mathrm{~min}$ incubation at room temperature. A total of $1 \mu \mathrm{L}$ of $1.25 \mathrm{mM} \mathrm{FeCl}_{2}$ was added to the reaction tube, mixed by centrifugation, and incubated for $1 \mathrm{~min}$ before adding $1 \mu \mathrm{L}$ of 12.5 $\mathrm{mM}$ sodium ascorbate. After $1 \mathrm{~min}, 1 \mu \mathrm{L}$ of $12.5 \mathrm{mM}$ hydrogen peroxide was added to initiate the reaction and rapidly mixed. The final concentrations were $250 \mu \mathrm{M}$ for $\mathrm{Fe}^{2+}$ and $2.5 \mathrm{mM}$ for both sodium ascorbate and hydrogen peroxide. The cleavage reaction was stopped after $1 \mathrm{~min}$ by the addition of $1 \mu \mathrm{L} 1 \mathrm{M}$ thio-urea, 1 $\mu \mathrm{L}$ glycogen $(10 \mu \mathrm{g} / \mu \mathrm{L})$, and $60 \mu \mathrm{L}$ ethanol. The RNA was precipitated, resuspended in gel-loading buffer $(0.3 \%$ each of bromophenol blue and xylenecyanol; $10 \mathrm{mM}$ EDTA (pH 7.5); $97.5 \%$ deionized formamide) and electrophoresed in denaturating $15 \%$ polyacrylamide sequencing gels.

$\mathrm{Mg}^{2+}$-competition of $\mathrm{Fe}^{2+}$-cleavage

In the $\mathrm{Mg}^{2+}$-competition experiment, the cleavage reaction was carried out in the presence of increasing amounts of $\mathrm{MgCl}_{2}(5-80$ $\mathrm{mM}$ ) leading to $\mathrm{Fe}^{2+}: \mathrm{Mg}^{2+}$ ratios ranging from 1:20 to 1:320, since $\mathrm{Fe}^{2+}$ shows a 100-fold higher affinity to tc than $\mathrm{Mg}^{2+}$ (Ettner et al. 1995). $\mathrm{MgCl}_{2}$ was added as a $5 \times$ stock solution of the final $\mathrm{Mg}^{2+}$ concentration to the $1.25 \mathrm{mM} \mathrm{FeCl}$ solution. The $\mathrm{Fe}^{2+} / \mathrm{Mg}^{2+}$ mixture was then pipetted into the reaction tube, and the cleavage reaction continued as above.

\section{Site-directed mutagenesis}

Mutations were introduced into pWHE601-AN32sh (wild-type aptamer) by directed PCR mutagenesis with the three primer method (Landt et al. 1990) using oligonucleotides carrying the respective nucleotide exchanges.

\section{GFP measurements}

Fluorescence measurements were done as previously described (Suess et al. 2003).

\section{ACKNOWLEDGMENTS}

The studies were carried out in the laboratory of Wolfgang Hillen, whose support is greatly appreciated. We thank Christian Berens,
Michael Müller, and Frank Walter for fruitful discussions and critical reading of the manuscript. We are grateful to the Volkswagenstiftung and the Fonds der Chemischen Industrie. S.H. was a recipient of a personal grant from the Boehringer Ingelheim Fonds, G.B. from the Fonds der Chemischen Industrie, and B.S. from the Bayerischer Habilitationsförderpreis.

Received November 29, 2004; accepted December 29, 2004.

\section{REFERENCES}

Balasubramanian, B., Pogozelski, W.K., and Tullius, T.D. 1998. DNA strand breaking by the hydroxyl radical is governed by the accessible surface areas of the hydrogen atoms of the DNA backbone. Proc. Natl. Acad. Sci. 95: 9738-9743.

Bauer, G., Berens, C., Projan, S.J., and Hillen, W. 2004. Comparison of tetracycline and tigecycline binding to ribosomes mapped by dimethylsulphate and drug-directed $\mathrm{Fe} 2+$ cleavage of $16 \mathrm{~S}$ rRNA. J. Antimicrob. Chemother. 53: 592-599.

Berens, C., Streicher, B., Schroeder, R., and Hillen, W. 1998. Visualizing metal-ion-binding sites in group I introns by iron(II)-mediated Fenton reactions. Chem. Biol. 5: 163-175.

Berens, C., Thain, A., and Schroeder, R. 2001. A tetracycline-binding RNA aptamer. Bioorg. Med. Chem. 9: 2549-2556.

Brodersen, D.E., Clemons Jr., W.M., Carter, A.P., Morgan-Warren, R.J., Wimberly, B.T., and Ramakrishnan, V. 2000. The structural basis for the action of the antibiotics tetracycline, pactamycin, and hygromycin B on the 30S ribosomal subunit. Cell 103: 1143-1154.

Celander, D.W. and Cech, T.R. 1990. Iron(II)-ethylenediaminetetraacetic acid catalyzed cleavage of RNA and DNA oligonucleotides: Similar reactivity toward single- and double-stranded forms. Biochemistry 29: 1355-1361.

Ehresmann, C., Baudin, F., Mougel, M., Romby, P., Ebel, J.P., and Ehresmann, B. 1987. Probing the structure of RNAs in solution. Nucleic Acids Res. 15: 9109-9128.

Ellington, A.D. and Szostak, J.W. 1990. In vitro selection of RNA molecules that bind specific ligands. Nature 346: 818-822.

Ettner, N., Ellestad, G.A., and Hillen, W. 1993. Enhanced site-specific cleavage of the tetracycline repressor by tetracycline complexed with iron. J. Am. Chem. Soc. 115: 2546-2548.

Ettner, N., Metzger, J.W., Lederer, T., Hulmes, J.D., Kisker, C., Hinrichs, W., Ellestad, G.A., and Hillen, W. 1995. Proximity mapping of the Tet repressor-tetracycline-Fe2+ complex by hydrogen peroxide mediated protein cleavage. Biochemistry 34: 22-31.

Hanson, S., Berthelot, K., Fink, B., McCarthy, J.E.G., and Suess, B. 2003. Tetracycline-aptamer-mediated translational regulation in yeast. Mol. Microbiol. 49: 1627-1637.

Hermann, T. and Patel, D.J. 2000. Adaptive recognition by nucleic acid aptamers. Science 287: 820-825.

Knapp, G. 1989. Enzymatic approaches to probing of RNA secondary and tertiary structure. Methods Enzymol. 180: 192-212.

Landt, O., Grunert, H.-P., and Hahn, U. 1990. A general method for rapid site-directed mutagenesis using the polymerase chain reaction. Gene 96: 125-128.

McMurry, L.M., Aldema-Ramos, M.L., and Levy, S.B. 2002. Fe(2+)tetracycline-mediated cleavage of the Tn10 tetracycline efflux protein TetA reveals a substrate binding site near glutamine 225 in transmembrane helix 7. J. Bacteriol. 184: 5113-5120.

Mironov, A.S., Gusarov, I., Rafikov, R., Lopez, L.E., Shatalin, K., Kreneva, R.A., Perumov, D.A., and Nudler, E. 2002. Sensing small molecules by nascent RNA. A mechanism to control transcription in bacteria. Cell 111: 747-756.

Nahvi, A., Sudarsan, N., Ebert, M.S., Zou, X., Brown, K.L., and Breaker, R.R. 2002. Genetic control by a metabolite binding mRNA. Chem. Biol. 9: 1043.

Nudler, E. and Mironov, A.S. 2004. The riboswitch control of bacterial metabolism. Trends Biochem. Sci. 29: 11-17. 
Patel, D.J., Suri, A.K., Jiang, F., Jiang, L., Fan, P., Kumar, R.A., and Nonin, S. 1997. Structure, recognition and adaptive binding in RNA aptamer complexes. J. Mol. Biol. 272: 645-664.

Pioletti, M., Schlunzen, F., Harms, J., Zarivach, R., Gluhmann, M., Avila, H., Bashan, A., Bartels, H., Auerbach, T., Jacobi, C., et al. 2001. Crystal structures of complexes of the small ribosomal subunit with tetracycline, edeine and IF3 EMBO J. 2: 1829-1839.

Soukup, J.A. and Soukup, G.A. 2004. Riboswitches exert genetic control through metabolite-induced conformational change. Curr. Opin. Struct. Biol. 14: 344-349.

Suess, B., Hanson, S., Berens, C., Fink, B., Schroeder, R., and Hillen, W. 2003. Conditional gene expression by controlling translation with tetracycline-binding aptamers. Nucleic Acids Res. 31: 18531858.

Tuerk, C. and Gold, L. 1990. Systematic evolution of ligands by exponential enrichment: RNA ligands to bacteriophage T4 DNA polymerase. Science 249: 505-510.

Tullius, T.D., Dombroski, B.A., Churchill, M.E., and Kam, L. 1987.
Hydroxyl radical footprinting: A high-resolution method for mapping protein-DNA contacts. Methods Enzymol. 155: 537-558.

Werstuck, G. and Green, M.R. 1998. Controlling gene expression in living cells through small molecule-RNA interactions. Science 282: 296-298.

Winkler, W.C. and Breaker, R.R. 2003. Genetic control by metabolitebinding riboswitches. Chembiochemisty 4: 1024-1032.

Winkler, W.C., Cohen-Chalamish, S., and Breaker, R.R. 2002a. An mRNA structure that controls gene expression by binding FMN. Proc. Natl. Acad. Sci. 99: 15908-15913.

Winkler, W.C., Nahvi, A., and Breaker, R.R. 2002b. Thiamine derivatives bind messenger RNAs directly to regulate bacterial gene expression. Nature 419: 952-956.

Winkler, W.C., Nahvi, A., Roth, A., Collins, J.A., and Breaker, R.R. 2004. Control of gene expression by a natural metabolite-responsive ribozyme. Nature 428: 281-286.

Zuker, M. 2003. Mfold Web server for nucleic acid folding and hybridization prediction. Nucleic Acids Res. 31: 3406-3415. 

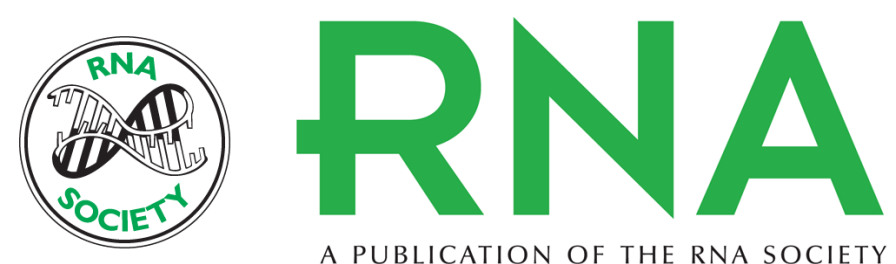

A PUBLICATION OF THE RNA SOCIETY

\section{Molecular analysis of a synthetic tetracycline-binding riboswitch}

SHANE HANSON, GESINE BAUER, BARBARA FINK, et al.

RNA 2005 11: 503-511

References This article cites 29 articles, 6 of which can be accessed free at:

http://rnajournal.cshlp.org/content/11/4/503.full.html\#ref-list-1

License

Email Alerting Receive free email alerts when new articles cite this article - sign up in the box at the Service top right corner of the article or click here. 